\title{
Mediating role of meaningful work between resources and work engagement in Bangladesh's private banks
}

\author{
Rubaba NAWRIN \\ National Institute of Development Administration, Bangkok, Thailand \\ rubaba.nawrin@gmail.com
}

\begin{abstract}
Engaged employees are considered as the most desired assets for the organization. Although significant contributions have been observed in the engagement literature, a holistic approach is yet to be untouched in terms of developing relationship between various resources, work engagement and psychological mechanism such as meaningful work. The purpose of this study is to explore the mediating role of meaningful work between resources and work engagement in private banks in Bangladesh. This study followed the quantitative methodological approach and based on Bakker and Demerouti's (2007) Job demand-resources model. A survey questionnaire was prepared and used to collect data. 440 respondents participated in this study, who is currently working in private banks in Bangladesh. Multiple regression analysis along with Sobel test was performed to analyze the data. The findings confirmed that the relationships between organizational, job, personal resources and work engagement were partially mediated through meaningful work. It has been observed that all determinates had a significant influence on work engagement. For practical implications, the organization can align various resources to uplift the engagement level of the employees. Since meaningful work was found to be a significant predictor, managers can develop jobs where employees can relate their purpose to their work. This study recommends that future research can apply this model to different contexts as well as to different groups of respondents.
\end{abstract}

Keywords: meaningful work, work engagement, organizational resources, job resources, personal resources

Please cite the article as follows: Nawrin, R. (2018), "Mediating role of meaningful work between resources and work engagement in Bangladesh's private banks", Management \& Marketing. Challenges for the Knowledge Society, Vol. 13, No. 1, pp. 777-795, DOI: 10.2478/mmcks-2018-0005.

\section{Introduction}

In today's organizations, employees are the driving force in attaining organizations' objectives. No strategic decision would ever be possible to accomplish without their efforts. The organizations can see the best results once employees have found themselves engaged with their work. Considered as an indispensable element, engaged employees also bring numerous benefits to an organization (Shuck and Wollard, 2010). Researchers admitted that employees who are engaged with their work are more energetic and make an extra effort to achieve the required success (Bakker and Schaufeli 2008; Bakker, 2009).

Over the past two decades, significant progress has been observed in engagement literature. Researchers have developed several theories and models to redefine the concept, antecedents and outcomes of work engagement. Despite this, four out of every ten employees are not engaged in their work and two out of every ten employees are actively disengaged (Albrecht et al., 2015). Such low levels of 
engagement have brought attention amongst the researchers who want to understand the determinants of engagement more deeply.

Researchers have claimed that understanding the relationship between various resources such as organizational, job and personal level resources and work engagement at a holistic approach can develop a new insight in this regard. To explore the relationship between the resources and work engagement in the holistic level, an important psychological mechanism is needed to be understood, i.e. meaningful work. Albrecht and $\mathrm{Su}$ (2012) found a mediating effect of meaningful work between job resources and work engagement. Thereby, they suggested seeing the role of meaningful work with organizational and personal level resources.

The current study has been conducted in the Bangladeshi private banking sector. The rapid growth of the private banks in Bangladesh increases the potential to compete in the larger context and able to contribute significantly in the nation's economy. While these progresses bring an opportunity to grow, concentration towards workforce and organization development becomes inevitable factors in the private banking sectors in Bangladesh. In this regard, the private banks should prioritize the development of a holistic framework addressing employees' work engagement perspectives. Though many studies have been conducted to build up measurement, conceptualization and antecedents development regarding engagement concept in the Western context, issues related to developing a framework of work engagement through organizational, job and personal resources along with meaningful work in South Asian context, especially in the Bangladesh Banking industry, are yet to be resolved. According to Albrecht (2012), identifying different constructs of the organizational, job and personal resources in different contexts with the association of meaningful work explain better the framework of work engagement. Therefore, the purpose of this study is to explore the role of meaningful work between resources (organizational, job, personal resources) and work engagement in the private banks in Bangladesh.

\section{Literature review}

\section{Job demand resources model}

To understand the resources and their relationship with work engagement, a job demand-resources (JD-R) model, which is a predominant framework in engagement literature, provides a holistic approach in understanding the job and its associates with regards to the individuals. This theoretical framework posits the psychological process of the individual in terms of job strain and motivation. While job demands such as poor job design produce negative job outcomes like exhaustion, job resources are considered a "motivation potential" (Bakker and Demerouti, 2007). By having appropriate job resources, employees can enjoy higher levels of engagement, job satisfaction and low cynicism (Bakker and Demerouti, 2007). Researchers identified several job resources that have influenced the employees to engage in their work. Job resources such as autonomy, support from the leader, coaching and opportunities for development were found to be major attributes which have a strong relationship with work engagement. According to Hakanen et al. (2006), job resources may encourage

Vol. 13, No. 1, Spring, pp. 777-795, ISSN 1842-0206 | Management \& Marketing. Challenges for the Knowledge Society 
employees to be interested in their work as well as increasing their engagement level. In addition, Xanthoupoulou et al. (2007) argued that personal characteristics such as self-esteem, self-efficacy, resiliency etc., also had a significant impact on individuals regarding the perception of the environment. Therefore, personal resources have become important elements in the JD- $\mathrm{R}$ model. A recent inclusion in the JD- $\mathrm{R}$ model along with job and personal resources is organizational resources. Albrecht (2012) suggested expanding the JD-R model by recognizing the impact of organizational level resources. He claimed that recognizing organizational level resources can enable the researchers to focus on resources from various backgrounds which will help to understand engagement, well-being, performance and so on. Although various types of resources have been examined with work engagement in different contexts, a holistic level approach has yet to be explored in an organization setting.

\section{Work engagement}

The concept of engagement started gaining interest in the last decade (Demerouti et al., 2001; Hallberg and Schaufeli 2006; Saks and Gruman 2011). Although consulting firms first brought this issue into the limelight, academics also demonstrated their interest in doing substantial research to develop the constructs, antecedents and outcomes of the variables. Through understanding work engagement as a motivational construct, the study is going to adopt the definition of Schaufeli et al. (2002). According to them, it is a "positive, fulfilling, work-related state of mind that is characterized by vigor, dedication, and absorption" (p. 72). Here, vigor refers to a high level of energy and mental resilience, an individual's willingness to put effort into their work and stay persistent during difficult periods. Dedication stands for the sense of enthusiasm, challenge, significance and pride at work and absorption refers to being fully engrossed and concentrating deeply leading to contentment and it becomes difficult to detach them even the time would be over.

\section{Organizational resources}

Organizational resources are a recent inclusion in JD-R model. They have been aligned to job resources in most of the previous studies (Salanova et al., 2006; Salanova et al. 2005). Albrecht (2012) first discussed detaching organizational level resources from job resources. He directed to elaborate the JD-R model by identifying and including organizational resources. According to him, recognizing this variable would bring new ideas for the researchers to enrich the JD-R model and develop new insights regarding employees' work engagement, employee well-being, and positive attitudes. Bakker et al. (2005) viewed it as a motivational antecedent for the employees in influencing their working process. The notion also reflected a reduction in job stress and an increase in employees' skills, and their personal growth and development (Demerouti et al., 2001). Therefore, the author of this research conceptualized organizational resources as a motivational construct provided by the organization to increase the efficiency level of their employees, stimulate further development of the self, and the organization when the job demands are high. According to Cable and Edwards (2004), organizations provide resources to their employees so that they can fulfill their requirements. The current study has identified five organizational resources, which

Vol. 13, No. 1, Spring, pp. 777-795, ISSN 1842-0206 | Management \& Marketing. Challenges for the Knowledge Society 
are organization climate, value congruence, HRM practices, fairness, and organization support, due to having an existing relationship with work engagement in previous literature. In their research, Halbesleben et al. (2009) recognized that the organization climate work as a necessary antecedent for engagement. Later on, Albrecht (2012) showed that organization climate has a strong association with work engagement through the influence of job resources. Also, Gillet et al. (2012) found a positive relationship between perceived organization support and work engagement. A positive relationship has also been observed between value congruence and work engagement (Sortheix et al., 2013). Moreover, the organization's HRM practices provide ideas to their employees how much they are valued and trusted by the organizations which leads to obligatory feelings for the employees of their organization. Therefore, the study proposes the following hypothesis:

H1: Organizational resources have a positive influence on work engagement.

\section{Job resources}

Job resources are one of the most important antecedents in work engagement. Emerging as an vital component in the JD-R model, job resources are defined as "those physical, psychological, social, or organization aspects of the job that are either/or (1) functional in achieving work goals (2) reduce job demands and the associated physiological and psychological costs (3) stimulate personal growth, learning, and development" (Bakker and Demerouti, 2007, p. 312). Acting as an intrinsic motivator, it fulfills the employees' basic needs (Deci and Ryan, 1985) whereas by allowing an extrinsic factor, it exerts their efforts towards their work (Gagné and Deci, 2005). As a process of intrinsic motivation, it has an impact on competence, autonomy, and relatedness (Ryan and Deci, 2000). For example, if the supervisor can give proper feedback to the employees, it not only boosts their motivational level but also increases their competence (Van den Broeck et al., 2008). In contrast, external factors, such as organization environment have an impact on the motivational process of the employees regarding their performance. For instance, if the compensation package is associated with the performance criteria, individuals take this resource as a positive approach moving further. In this study, following job resources characteristics will be examined: autonomy, social support, task significance, opportunities for learning and development, and performance feedback. Halbesleben (2010) found that autonomy, skill utilization, professional development, and social support were related to engagement, job satisfaction and health. Schaufeli and Taris (2014) claimed that feedback about performance could enhance the learning opportunities of the employees that leading to an increase in their competence as well. Hu et al. (2013) investigated the relationship effect of job demand and job resources on employee well-being and found a positive association between job resources and work engagement. The above discussion leads to developing the following hypothesis:

H2: Job resources positively influence work engagement. 


\section{Personal resources}

Personal resources are considered an essential part of employee well-being (Albrecht, 2012). Personal resources are defined as the "lower-order, cognitive-affective aspects of personality; developable systems of positive beliefs about one's 'self' (e.g., selfesteem, self-efficacy) and the world (e.g., optimism, faith) which motivate and facilitate goal-attainment, even in the face of adversity" (Van Den Heuvel et al., 2010, p.129). Personal resources occur as a motivational process like job resources that assist attaining work goals and help improve personal growth (Schaufeli and Taris, 2014). In this study, five general personal resources, namely self-efficacy, organization-based self-esteem, optimism, hope and resiliency have been chosen as constructs. Xanthoupoulou et al. (2009) found that personal resources (self-efficacy, optimism, and organization based self-esteem) predicted work engagement. In another study, Xanthoupoulou et al. (2013), investigated a two-wave study where personal resources (self-efficacy and optimism) buffer emotional demand and emotional rule dissonance over work engagement. The result reflected that in a buffering situation; when self-efficacy was low, emotional demand and dissonance portrayed a negative relationship with work engagement. On the other hand, in a boosting situation, self-efficacy had a positive relationship with work engagement. Bakker and Xanthoupoulou (2013) identified the intervening role of personal resources (self-efficacy and resiliency) in two leadership behaviors, i.e. creativity and charismatic leadership qualities among female school principals. In their study, they explored how personal resources partially mediate the relationship between job resources and work engagement and how they indirectly affect the leadership behaviors of the school principals. Acting as a strong predictor of work engagement, the following hypothesis could be derived.

H3: Personal resources have a positive influence on work engagement.

\section{Meaningful work}

Meaningful work is a complex, multidimensional construct in organization literature, and has been conceptualized through various perspectives by researchers. This study is going to adopt the definition of meaningful work from May et al's. (2004) work. According to them, meaningful work is defined as the individual's value regarding the work goal according to their own standard.

Meaningful work has a significant impact on an individual's perception towards employees' work engagement. A growing number of researchers have studied the concept of meaningful work within the context of work engagement (Chalofsky and Krishna, 2009). Fairlie (2011) identified a strong correlation between employees' work engagement and meaningful work. Soane et al. (2013) examined the mediating and moderating factors that are associated with employees' perception of work and absence. The results depicted that meaningful work increases the level of work engagement. The results also showed that work engagement mediates the relationship between meaningful work and absenteeism. According to Holbeche and Springett (2004), as employees spend a significant amount of their time in the workplace, it is essential for them to find the purpose or meaning of their work. They 
also claimed that individuals prefer to leave an organization if they cannot locate the meaning of their work. This discussion can generate the following hypothesis:

H4: Meaningful work has a positive influence on work engagement.

\section{Mediating role of meaningful work between resources and work engagement}

To motivate employees and retain them, understanding the deeper needs of the individual is required (Cartwright and Holmes, 2006). Experiencing meaningful work can help the organization to achieve optimum outcomes for the employees (Steger et al., 2012). Kahn (1990) claimed that people invest or withdraw themselves based on their psychological experience in their role.

The motivational potential of the resources develops the work meaningful for the employees (Salanova et al., 2006). Albrecht (2012) showed that organizational resources have a strong influence over work engagement and he predicted that individuals' psychological state towards meaningful work might influence the relationships between organizational resources and work engagement. In another sense, a lack of organizational resources is responsible for creating de-motivation among employees towards their work (Salanova et al., 2006) which can create disengagement among the employees. Similar assumptions also lead to job and personal resources. According to Schaufeli and Bakker (2004), the intrinsic motivational aspect of job resources increases employees' growth and personal development by fulfilling basic human needs. Therefore, job resources act as a predictor for creating meaningful work in work environment (Clausen and Borg, 2011). If the work environment cannot provide sufficient level for job resources, the motivation towards achieving the task, most importantly, the effort made by employees will be hindered, and eventually they will be disengaged (Bakker and Demerouti, 2008). Albrecht (2013) explained the necessity to understand the psychological process between personal resources and work engagement. In his conceptual framework, he developed the idea of seeing how the need for satisfaction of meaningful work could influence personal resources and work engagement. Personal resources such as optimism, resilience, self-efficacy, and hope might have an influence of the psychological experience of meaningful work (Albrecht, 2013). He developed a comprehensive conceptual framework whereby he tried to convey how personal resources could influence the need for satisfaction of meaningful work to result in work engagement. In another piece of research, Jacob (2013) found that job features and personal characteristics affect work engagement through psychological conditions of meaningful work, safety, and availability. According to Steger et al. (2012), it is important to understand which personality trait or values could lead to experiencing meaningfulness. Based on the above discussion, the following hypotheses have been developed:

H5: Meaningful work mediates the relationship between organizational resources and work engagement.

H6: Meaningful work mediates the relationship between job resources and engagement.

H7: Meaningful work mediates the relationship between personal resources and work engagement.

Vol. 13, No. 1, Spring, pp. 777-795, ISSN 1842-0206 | Management \& Marketing. Challenges for the Knowledge Society 


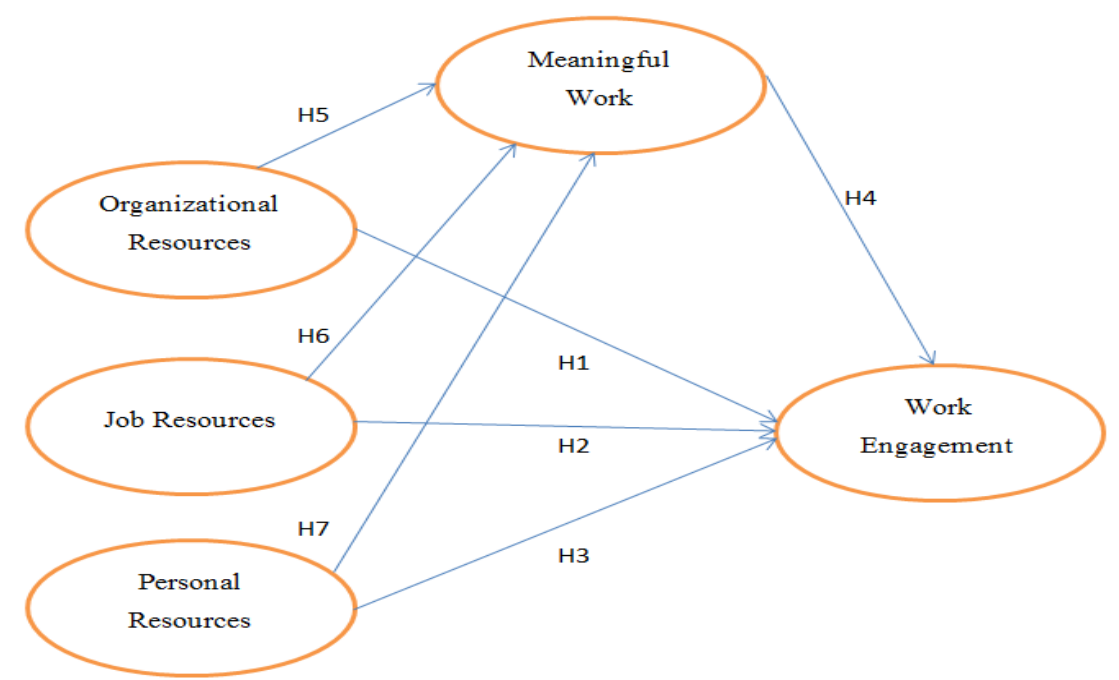

Figure 1. Mediating role of meaningful work between resources and work engagement

Source: Author's own research.

\section{Research methodology Sample and procedure}

The purpose of the study was to investigate the role of meaningful work between resources and work engagement. The study was conducted in the private banking sector in Bangladesh. A convenient sampling method was used to select the participants. Out of 500 respondents, 440 respondents participated in this study. A self-administered survey method has been used to assess the variables. The questions were formulated by using a five point Likert scale format.

\section{Variables and measurement scales}

Work engagement was evaluated by using the Utrecht Work Engagement Scale (UWES) developed by Schaufeli et al. (2006). The questionnaire consisted of three subscales: vigor, dedication, and absorption. 12 items were selected to conduct the current study. Meaningful work was evaluated by using the meaningful work scale that was developed by Steger et al. (2012). 4 items were selected to conduct this study. Organization climate was evaluated by the scale developed by Rogg et al. (2001). 5 items were selected to conduct this study. Organization support was evaluated by the scale developed by Saks (2006). 4 items were selected to conduct this study. Value congruence was evaluated by the scale developed by Thomas (2013). 4 items were selected to conduct this study. HRM practices was evaluated by the scale developed by Gould-Williams and Davies (2005). 4 items were selected to conduct this study. Fairness was evaluated by the scale developed by Gould-Williams and David (2005). 4 items were selected to conduct this study. Autonomy was evaluated by the scale developed by Morgeson and Humphrey (2006). 4 items were selected to conduct this study. Social support was evaluated by the scale developed by Morgeson and Humphrey (2006). 4 items were selected to conduct this study. Performance feedback was evaluated by the scale developed by Morgeson and Humphrey (2006). 3 
items were selected to conduct this study. Task significance was evaluated by the scale developed by Morgeson and Humphrey (2006). 3 items were selected to conduct this study. Opportunities for learning and development were evaluated by the scale developed by van Veldhoven and Meijman (1994). 4 items were selected to conduct this study. Self-efficacy was evaluated by the scale developed by Sapyaprapa et al. (2013). 4 items were selected to conduct this study. Organization based self-esteem was evaluated by the scale developed by Pierce et al. (1989). 4 items were selected to conduct this study. Hope was evaluated by the scale developed by Sapyaprapa et al. (2013). 3 items were selected to conduct this study. Resiliency was evaluated by the scale developed by Sapyaprapa et al. (2013). 4 items were selected to conduct this study. Optimism was evaluated by the scale developed by Sapyaprapa et al. (2013). 4 items were selected to conduct this study.

\section{Results}

\section{Descriptive statistics}

$74.8 \%$ males and $25.2 \%$ females took part in this survey. $51.4 \%$ respondents were in the age group of 31-40 years old and $45.7 \%$ were in between 21 and 30 years old. The majority of them were working at the mid-level position $(47.0 \%)$ in the organization, while most of them serving the organization around three years $(40.5 \%)$. The respondents' education was also equally divided into banking and non-banking backgrounds. $50.9 \%$ of the employees had studied business administration in their graduate level. $49.1 \%$ respondents had a different academic background.

\section{Multiple regression analysis}

This research follows Barron and Kenny's (1986) method of conducting mediation analysis. To confirm the mediation analysis, first, all the independent variables (OR, JR and PR) must predict the mediating variable of meaningful work (MW). Second, the mediator, meaningful work, must influence the dependent variable work engagement (WE). Third, a significant influence will be observed between the relationship of the independent (OR, JR, and PR) and dependent variables (WE) by adding a mediator (MW). After adding the mediating variable, MW, if the influence is reduced, it will be considered a partial mediation whereas if the relationship becomes insignificant, it will be noted a full mediation. For condition three, the resources must predict work engagement.

Therefore, it is observed in Table 1 that, in step 1, the resources were regressed with the mediating variable meaningful work. All the resources were depicted as significant positive influences with meaningful work $\left(\mathrm{OR}=1.00^{*}\right.$, $\mathrm{JR}=.333^{* * *}, \mathrm{PR}=.245^{* * *}$ ). In step 2 , meaningful work significantly influenced work engagement $\left(\beta=.686^{* * *}\right)$. This result confirms hypothesis 4 . In step $3(\mathrm{a})$, all the resources had regression with work engagement and they showed a significantly positive influence between the variables $\left(\mathrm{OR}=.241^{* * *}, \mathrm{JR}=.280^{* * *}, \mathrm{PR}=.301^{* * *}\right.$ ). Thus, it confirms the hypotheses 1, 2 and 3. The mediation effect is observed in step 3(b) while adding a mediating variable along with the independent variables. After adding meaningful work, a significant influence was observed but the influence of the resources became less strong which could conclude of existence of partial mediation

Vol. 13, No. 1, Spring, pp. 777-795, ISSN 1842-0206 | Management \& Marketing. Challenges for the Knowledge Society 
in the model. The result is best described in Table 2. Table 2 depicted that the total effect between organizational resources and work engagement was $\beta=.241, p=.000$, which was reduced after adding meaningful work. Therefore, the direct effect of organizational resources on work engagement was $\beta=.198, p=.000$. Similar observations were also found in two other resources. The total effect of job and personal resources on work engagement were $\beta=.280, p=.000$ and $\beta=.301, p=.000$ respectively. Both of the resources showed significantly less influence on work engagement after adding meaningful work. Therefore, the direct effect of job and personal resources on work engagement were $\beta=.137, p=.000$ and $\beta=.196, p=.000$ respectively.

Mediation in the relationship existed when the indirect effect became lower than the total effect. According to Mathieu and Taylor (2006), indirect effect is considered a form of an intervening effect that the predictors and dependent variable are related to indirectly by having a significant relationship. In table 2 , it is depicted that the indirect effect of OR, JR and PR were .043, .143, and.105 respectively which were lower than the total effect.

To see the magnitude of the mediation effect, the Sobel (1982) $z$ test was performed. The Sobel test showed the significance of an indirect effect in table 2 . If the indirect effect was not significant, it was considered a full mediation. On the other hand, partial mediation existed when the indirect effect was significant. The result showed that meaningful work partially mediated the relationship between organizational, job, personal resources and work engagement $(z=.043, \mathrm{p}=.001, z=$ $.143, p=.001, z=.105, p=.001$ respectively). Therefore, hypotheses 5,6 and 7 have been proven.

Table 1. Multiple Regression Analysis

\begin{tabular}{|l|l|l|l|}
\hline Step 1 Independent variables (OR, JR, and PR) & predicts mediating variable (MW) \\
\hline Variables & $\boldsymbol{\beta}$ & $\mathbf{t}$ & $\mathbf{p}$ \\
\hline Organizational Resources & .100 & 1.872 & .062 \\
\hline Job Resources & .333 & 5.855 & .000 \\
\hline Personal Resources & .245 & 5.087 & .000 \\
\hline Step 2 Mediating variable (MW) predicts dependent variable (WE) \\
\hline Variables & $\boldsymbol{\beta}$ & $\mathbf{t}$ & $\mathbf{p}$ \\
\hline Meaningful Work & .686 & 19.708 & .000 \\
\hline Step 3 (a) Independent variables (OR, JR, and PR) predicts dependent variable (WE) & p \\
\hline Variables & $\boldsymbol{\beta}$ & $\mathbf{t}$ & .000 \\
\hline Organizational Resources & .241 & 5.092 & .000 \\
\hline Job Resources & .280 & 5.553 & .000 \\
\hline Personal Resources & .301 & 7.063 & $\mathbf{p}$ \\
\hline $\begin{array}{l}\text { Step 3 (b) Independent (OR, JR, and PR) and mediating variable (MW) predicts dependent } \\
\text { variable (WE) }\end{array}$ & $\boldsymbol{\beta}$ & t & .000 \\
\hline Variables & .429 & 11.545 & .000 \\
\hline Meaningful Work & .198 & 4.759 & .003 \\
\hline Organizational Resources & .137 & 2.987 & .000 \\
\hline Job Resources & .196 & 5.101 & . \\
\hline Personal Resources &
\end{tabular}

Source: Author's own research

OR: Organizational resources; JR: Job resources; PR: Personal resources; MW: Meaningful work; WE: Work engagement 
Table 2. Mediation Effect

\begin{tabular}{|l|l|l|l|l|l|l|l|}
\hline \multicolumn{2}{|l|}{ Relationship } & \multicolumn{3}{|l|}{ Total Effect (C) } & \multicolumn{2}{l|}{ Direct Effect (C) } & \multicolumn{2}{l|}{$\begin{array}{l}\text { Indirect Effect (using } \\
\text { Sobel, } \boldsymbol{z}, \text { test) }\end{array}$} \\
\cline { 3 - 9 } & $\boldsymbol{\beta}$ & $\mathbf{p}$ & $\boldsymbol{\beta}$ & $\mathbf{p}$ & $\mathbf{B}$ & $\mathbf{P}$ \\
\hline Model 1 & OR-MW-WE & .241 & .000 & .198 & .000 & .043 & .063 \\
\hline Model 2 & JR-MW-WE & .280 & .000 & .137 & .003 & .143 & .000 \\
\hline Model 3 & PR-MW-WE & .301 & .000 & .196 & .000 & .105 & .000 \\
\hline
\end{tabular}

Source: Author's own research OR: Organizational resources; JR: Job resources; PR: Personal resources; MW: Meaningful work; WE: Work engagement

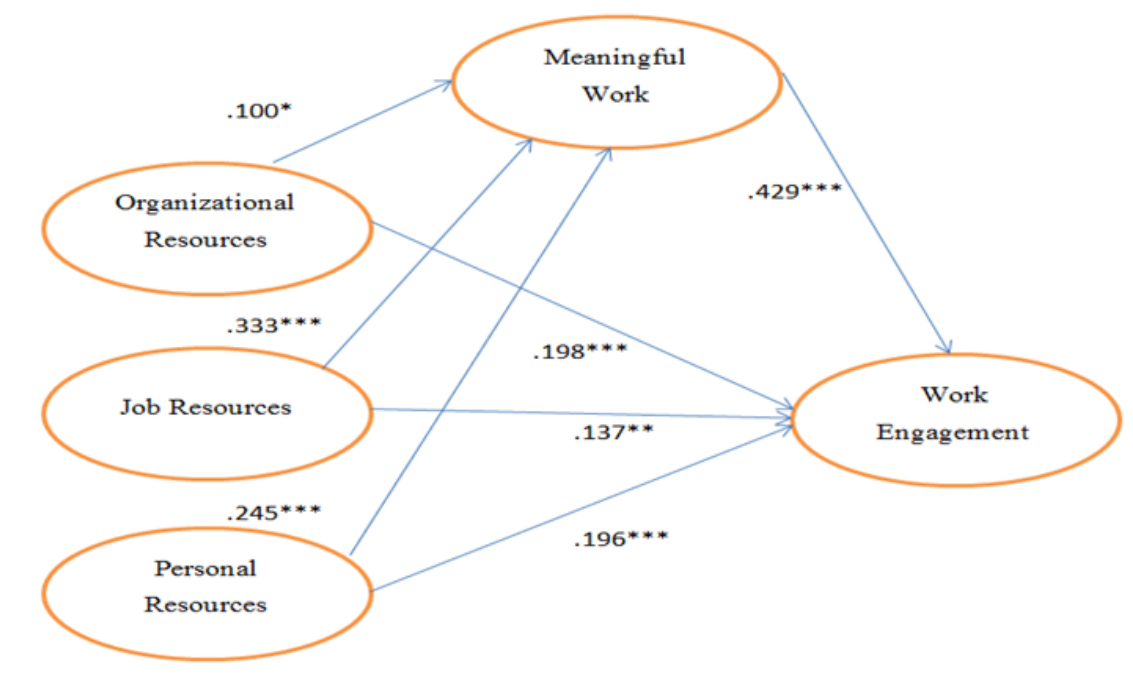

$* * *$ Correlation is significant at the .01 level (2-tailed).

** Correlation is significant at the .05 level (2-tailed).

*Correlation is significant at the .10 level (2-tailed).

Figure 2. Partial mediation effect of meaningful work between resources and work engagement

Source: Author's own research.

\section{Discussion}

The study examined the mediating role of meaningful work between the resources (i.e. organizational resources, job resources and personal resources) and work engagement. The result showed that meaningful work partially mediates the relationship between organizational, job, personal resources and work engagement. Similar findings have been observed in previous literature. While exploring the mechanisms of the JD-R model, researchers found the mediating effect of meaningful work between job resources and work engagement (Albrecht and $\mathrm{Su}, 2012$ ). Suggestions were given by the researchers to explore the mediation effect of meaningful work between other resources, such as organizational and personal resources, and work engagement (Albrecht and Su, 2012). Thus, this study is first 
going to present the result of the mediating effect of meaningful work between personal, organizational resources and work engagement.

The partial mediation effect of meaningful work was observed between organizational resources and work engagement. Organizational resources such as organization climate, value congruence, fairness, HRM practices, and organization support were found to be important antecedents of work engagement as they have a significant influence on work engagement. However, the direct influence altered once meaningful work took place. It was observed that the relationship effect between organizational resources and work engagement became low once meaningful work entered into the relationship. Meaningful work creates a significant impact on employees' working conditions. Employees were found to be more engaged while receiving a higher degree of organizational resources. For an example, this study explored how a positive organization climate, fairness, and good HRM practices influences employees to be more motivated and goal-oriented and this, therefore, influences their work performance. Bakker et al. (2007) explored how an organizational climate stimulates the job to become more interesting, challenging and growth oriented and how employees found themselves more attached and engaged to perform their tasks. This situation has an interesting turn while the employees found their job as meaningful. When individuals found a purpose in their work, their motivation level increased significantly (Baumeister, 1991). Organizational resources can create the work meaningful for their employees. Gelade and Ivery (2003) found that through the HRM system, an organization can form a meaningful work environment for its employees. In a meaningful environment, employees found themselves a significant contributor as well as having valuable elements for the organization. These attributes eventually allowed the employees to be more engaged towards their work.

The study also revealed that meaningful work partially mediated job resources and work engagement. Job resources such as autonomy, performance feedback, opportunities for learning and development, task significance and social support were found to be strong predictors of work engagement. Moreover, the level of employees' work engagement improved once they found their job was meaningful and it met the purpose of why they were doing the job. When job resources created work which was meaningful for their employees, they tended to be more engaged towards their work. Similar findings have been observed in previous literature (Albrecht and $\mathrm{Su}, 2012$ ). In their research, Albrecht and Su (2012) identified that psychological mechanisms such as meaningfulness, felt obligation and mood mediated the relationship between job resources and work engagement in a Chinese telecom company. According to their finding, job resources such as autonomy, performance feedback and colleague support influence the psychological need of the employees and eventually influence his engagement condition. Kahn (1990) identified that job resources such as task characteristics, role characteristics and work interaction played significant roles on work engagement and meaningful work had full mediation between these variables. May et al. (2004) found that job enrichment, co-worker relation and work role fit were the prime determinants of meaningful work that influence work engagement. 
The study also depicted the partial mediating role of meaningful work between personal resources and work engagement. Personal resources such as self-efficacy, organization-based self-esteem, optimism, hope and resiliency were found to be strong antecedents of work engagement. Previous studies have confirmed the positive influence between personal resources and work engagement. Karatepe and Olugbade (2009) found that self-efficacy was one of the personal resources that enhanced the level of employee's work engagement. According to them, employees who are competitive and believe in themselves can be fully engrossed in their work. Similar findings were also observed by Xanthoupoulou et al. (2007), who found a positive association with self-efficacy, self-esteem and optimism and work engagement. Employees who believe in themselves are more confident, optimistic and competitive, which influences them to become more engaged in their job. Other research also portrayed the same conclusion. In their study on police officers, Storm and Rothmann (2003) found that police officers who were optimistic, self-efficient and pursued active coping styles tended to be more engaged than others. In a longitudinal study, Bakker et al. (2008) investigated how personal resources such as self-efficacy and optimism greatly influenced work engagement over a time period. In another study, Othman and Nasurdin (2011) explored the positive associations between hope, resilience and work engagement. Employees who were resilient tended to be more engaged to their work. Wilson and Ferch (2005) found that resilience enables employees to be more flexible and adapt to changes that influence their performance levels.

From the theoretical perspective, the findings support the motivational background of JD-R model. According to the theory, resources can fulfill the intrinsic need of the individual that enhance the motivation process of the employees and create positive attitude towards their work (Bakker and Demerouti, 2008). In addition, Hobfoll's (1989) conservation of resources (COR) theory also pertains with the current findings. The theory reflects the motivational influence through availability of resources as claimed by JD-R model. It also added that individuals have a tendency to accumulate resources to strengthen the existing ones. This accumulation eventually makes the employees more motivated and engaged towards their work (Hobfoll, 1989; Xanthoupoulou et al., 2009). Furthermore, the pattern of findings also aligns with social exchange theory, which deals with the reciprocate relationship between elements. According to social exchange theory, employees become more obliged to their duties if sufficient resources are provided and job becomes meaningful to them (Albrecht, 2013). As a reciprocate nature, the availability of the resources enables the employees to become more energized, motivated and engaged towards their job (Saks, 2006).

In the context of Bangladesh private banking sector, this research creates new knowledge to understand the influence of meaningful work between resources and work engagement. As lack of empirical evidence is showing in Bangladesh context, this research brings new light to understand the psychological mechanism that influences the relationship between organizational, job, personal resources and work engagement. 


\section{Implications}

\section{Implications for research}

The engagement literature is mostly dominated by its outcome knowledge. However, researchers have discussed focusing on the process of work engagement (Chalofsky and Krishna 2009). Moreover, developing a work engagement relationship with antecedents of various types of the resource has not been studied on a large scale. In this study, the author has created an extended framework, including organizational, job, and personal resources, where the engagement literature will explore its antecedents in broader perspectives through the lens of meaningful work. Moreover, this research will also bring new knowledge about organizational resources as not much research has been carried out on this subject. Therefore, the process of developing work engagement will contribute with new knowledge to the literature.

Another important variable in this research is meaningful work. Playing a mediating role, new insights into this variable regarding the psychological process in both the JD-R framework and engagement literature will be generated. Though previous studies supported the relationship between meaningful work and work engagement as well as job resources and meaningful work, the relationship with personal resources and organizational resources has yet to be discovered. Researchers often approach positive psychological behavior when they work on engagement issues. Seligman and Csikszentmihalyi (2000) stated that engagement is highly dependent on the conditions where individuals flourish.

As organizational resources are considered an extended new variable in the JD$\mathrm{R}$ framework, the concept needs intense analysis for deeper understanding. In this regard, the current study will build up an idea which suits the JD-R framework more. Developing constructs for this variable will add new prospects for conducting research in different contexts. Moreover, considering a significant predictor of work engagement will enhance the JD-R model through its motivation process (Albrecht, 2012).

\section{Implications for practitioners}

The current study could provide a better concept than the previous ones regarding the process and procedures of work engagement. Serrano and Reichard (2011) stated that to prevent disengagement, the managers should be well-aware of the engagement process. Therefore, it will be expected from training managers to develop an integrated training and development program to improve the level of work engagement in their employees. The study will facilitate the current organization setting regarding engagement issues as every year the organizations put tremendous effort, both financial and non-financial, in increasing the engagement level of the employees.

Furthermore, management will be able to understand different types of resources well and identify the ones that are suitable for their organizational context. Through this, employees will also learn which resources they should focus on more. Through psychological intervention such as meaningful work, employers can provide better opportunities to engage employees, as their work engagement level varies according to their psychological needs (Albrecht and $\mathrm{Su}, 2012$ ).

Vol. 13, No. 1, Spring, pp. 777-795, ISSN 1842-0206 | Management \& Marketing. Challenges for the Knowledge Society 
From the practitioner's report, it has been seen that due to disengagement, organizations incur a huge loss (Gallup, 2013). The evidence-based model of this study will help organizations to reshape training programs as per the requirements of the context. Besides, the study will also help the decision-makers to view these perspectives from a new angle. For example, senior management will have an opportunity to redesign the job through understanding the context of the organization, providing participative workplace culture for the employees, developing an engagement focused training program and so on. Interventions to improve the process of work engagement will also be stimulated through the development of the feedback process (Albrecht, 2012).

\section{Conclusion and future research}

This study investigated the mediating role of meaningful work between resources and work engagement in Bangladeshi private banks. A partial mediation has been witnessed among the variables. Organizational, job and personal resources have found to be a direct relationship with work engagement. After intervening of meaningful work as a mediator, the relationships turned into an indirect effect. Therefore, the result confirmed the partial effect of meaningful work between resources and work engagement.

In addition, the result also confirmed the proposed model. The model well explained how the engagement level of the employees enhanced through resources with a mediating impact of meaningful work. Therefore, the model can be a source of future studies to extend the understandings of the variables. This study eventually provides several research outcomes that may help both the practitioners, organizations and academics. The organization can design and build its resources to uplift the engagement level of the employees with the assistance of creating meaningful work.

Future research of this study can be done through validating the results in different organizational setting. Different methodological approaches could be followed to observe the variables. A mixed method can be used to understand the phenomena in details. A new set of respondents can also validate the result. The researchers can also develop the scale according to the understanding of different cultural settings.

\section{References}

Albrecht, S.L. (2012), “The influence of job, team and organizational level resources on employee well-being, engagement, commitment and extra-role performance: Test of a model", International Journal of Manpower, Vol. 33, No. 7, pp. 840853.

Albrecht, S.L. (2013), "Work engagement and the positive power of meaningful work", in: Bakker, A. B. (eds.) Advances in positive organizational psychology, pp. 237-260, Emerald Group Publishing Limited: UK.

Albrecht, S.L. and Su, M.J. (2012), “Job resources and employee engagement in a Chinese context: the mediating role of job meaningfulness, felt obligation 
and positive mood", International Journal of Business and Emerging Markets, Vol. 4, No. 4, pp.277-292.

Albrecht, S.L., Bakker, A.B., Gruman, J.A., Macey, W.H. and Saks, A.M. (2015), "Employee engagement, human resource management practices and competitive advantage: An integrated approach", Journal of Organizational Effectiveness: People and Performance, Vol. 2, No. 1, pp. 7-35.

Bakker, A.B. (2009), "Building engagement in the workplace”, in: Bruke, R. J., and Cooper, C. L. (eds.) The peak performing organization, pp. 50-72, Routledge: UK.

Bakker, A.B. and Demerouti, E. (2007), "The job demands-resources model: State of the art", Journal of Managerial Psychology, Vol. 22, No. 3, pp.309-328.

Bakker, A.B. and Demerouti, E. (2008), "Towards a model of work engagement", Career development international, Vol. 13, No. 3, pp.209-223.

Bakker, A.B. and Schaufeli, W.B. (2008), "Positive organizational behavior: Engaged employees in flourishing organizations", Journal of Organizational Behavior, Vol. 29, No. 2, pp. 147-154.

Bakker, A.B. and Xanthopoulou, D. (2013), "Creativity and charisma among female leaders: the role of resources and work engagement", The International Journal of Human Resource Management, Vol. 24, No. 14, pp. 2760-2779.

Bakker, A.B., Demerouti, E. and Euwema, M.C. (2005), "Job resources buffer the impact of job demands on burnout", Journal of Occupational Health Psychology, Vol. 10, No. 2, pp. 170-180.

Bakker, A.B., Hakanen, J.J., Demerouti, E. and Xanthopoulou, D. (2007), “Job resources boost work engagement, particularly when job demands are high", Journal of Educational Psychology, Vol. 99, No.2, pp. 274-284.

Bakker, A.B., Schaufeli, W.B., Leiter, M.P. and Taris, T.W. (2008), "Work engagement: An emerging concept in occupational health psychology", Work \& Stress, Vol. 22, No. 3, pp. 187-200.

Barron, R.M. and Kenny, D.A. (1986), "The moderator-mediator variable distinction in social psychological research: Conceptual, strategic, and statistical considerations", Journal of Personality and Social Psychology, Vol. 51, No.6, pp. 1173-1182.

Baumeister, R.F. (1991), "Meanings of life”, Guilford Press, NY.

Cable, D.M. and Edwards, J.R. (2004), "Complementary and supplementary fit: a theoretical and empirical integration", Journal of Applied Psychology, Vol. 89, No. 5, pp. 822-834.

Cartwright, S. and Holmes, N. (2006), "The meaning of work: The challenge of regaining employee engagement and reducing cynicism", Human Resource Management Review, Vol. 16, No. 2, pp. 199-208.

Chalofsky, N. and Krishna, V. (2009), "Meaningfulness, commitment, and engagement: The intersection of a deeper level of intrinsic motivation", Advances in Developing Human Resources, Vol. 11, No. 2, pp. 189-203.

Clausen, T. and Borg, V. (2011), "Job demands, job resources and meaning at work", Journal of Managerial Psychology, Vol. 26, No. 8, pp. 665-681.

Deci, E.L., and Ryan, R.M. (1985), "Intrinsic motivation and self-determination in human behavior", Plenum: New York and London. 
Demerouti, E., Bakker, A.B., Nachreiner, F. and Schaufeli, W.B. (2001), "The job demands-resources model of burnout", Journal of Applied Psychology, Vol. 86, No. 3, pp. 499-512.

Fairlie, P. (2011), "Meaningful work, employee engagement, and other key employee outcomes: Implications for human resource development", Advances in Developing Human Resources, Vol. 13, No. 4, pp. 508-525.

Gagné, M. and Deci, E.L. (2005), "Self-determination theory and work motivation", Journal of Organizational Behavior, Vol. 26, No. 4, pp. 331-362.

Gallup Poll (2013), "State of the global workplace: Employment engagement insights for business leaders worldwide", Gallup News, available at: http://news.gallup.com/reports/220313/state-global-workplace2017.aspx\#aspnetForm/ (accessed August 15, 2017).

Gelade, G.A. and Ivery, M. (2003), "The impact of human resource management and work climate on organizational performance", Personnel Psychology, Vol. 56, No. 2, pp. 383-404.

Gillet, N., Huart, I., Colombat, P. and Fouquereau, E. (2012), “Perceived organizational support, motivation and engagement among police officers", Professional Psychology: Research and Practice, Vol. 44, No. 1, pp. 46-55.

Gould-Williams, J. and Davies, F. (2005), "Using social exchange theory to predict the effects of HRM practice on employee outcomes: An analysis of public sector workers”, Public Management Review, Vol. 7, No. 1, pp. 1-24.

Hakanen, J.J., Bakker, A.B. and Schaufeli, W.B. (2006), "Burnout and work engagement among teachers", Journal of School Psychology, Vol. 43, No. 6, pp. 495-513.

Halbesleben, J.R. (2010), “A meta-analysis of work engagement: Relationships with burnout, demands, resources, and consequences", in: Bakker, A. B. and Leiter, M. P. (eds.) Work engagement: A handbook of essential theory and research, Vol. 8, pp. 102-117, Psychology Press: NY.

Halbesleben, J.R., Harvey, J. and Bolino, M.C. (2009), “Too engaged? A conservation of resources view of the relationship between work engagement and work interference with family", Journal of Applied Psychology, Vol 94, No. 6, pp. 1452-1465.

Hallberg, U.E. and Schaufeli, W.B. (2006), "Same same" but different? Can work engagement be discriminated from job involvement and organizational commitment?", European Psychologist, Vol. 11, No. 2, pp. 119-127.

Hobfoll, S.E. (1989), "Conservation of resources: A new attempt at conceptualizing stress", American Psychologist, Vol. 44, No. 3, pp. 513-524.

Holbeche, L. and Springett, N. (2004), "In search of meaning at work", Roffey Park Institute: Horsham.

Hu, Q., Schaufeli, W.B. and Taris, T.W. (2013), “Does equity mediate the effects of job demands and job resources on work outcomes? An extension of the job demands-resources model", Career Development International, Vol. 18, No. 4, pp. 357-376.

Jacobs, H. (2013), "An examination of psychological meaningfulness, safety, and availability as the underlying mechanisms linking job features and personal characteristics to work engagement", DP thesis, Florida International University, Florida. 
Kahn, W.A. (1990), "Psychological conditions of personal engagement and disengagement at work." Academy of Management Journal, Vol. 33, No. 4, pp. 692-724.

Karatepe, O.M. and Olugbade, O.A. (2009), "The effects of job and personal resources on hotel employees' work engagement", International Journal of Hospitality Management, Vol. 28, No. 4, pp. 504-512.

Mathieu, J.E. and Taylor, S.R. (2006), "Clarifying conditions and decision points for mediational type inferences in organizational behavior", Journal of Organizational Behavior, Vol. 27, No. 8, pp. 1031-1056.

May, D.R., Gilson, R.L. and Harter, L.M. (2004), "The psychological conditions of meaningfulness, safety and availability and the engagement of the human spirit at work", Journal of Occupational and Organizational Psychology, Vol. 77, No. 1, pp. 11-37.

Morgeson, F.P. and Humphrey, S.E. (2006), "The Work Design Questionnaire (WDQ): developing and validating a comprehensive measure for assessing job design and the nature of work", Journal of Applied Psychology, Vol. 91, No. 6, pp. 1321-1339.

Othman, N. and Nasurdin, A.M. (2011), "Work engagement of malaysian nurses: exploring the impact of hope and resilience", World Academy of Science, Engineering and Technology, Vol. 60, pp. 1702-1706.

Pierce, J.L., Gardner, D.G., Cummings, L.L. and Dunham, R.B. (1989), “Organization based self-esteem: Construct definition, operationalization and validation", Academy of Management Journal, Vol. 32, No. 3, pp. 622-648.

Rogg, K.L., Schmidt, D.B., Shull, C. and Schmitt, N. (2001), "Human resource practices, organizational climate, and customer satisfaction", Journal of Management, Vol. 27, No. 4, pp. 431-449.

Ryan, R.M. and Deci, E.L., 2000. "Self-determination theory and the facilitation of intrinsic motivation, social development, and well-being", American Psychologist, Vol. 55, No.1, pp. 68-78.

Saks, A.M. (2006), "Antecedents and consequences of employee engagement”, Journal of Managerial Psychology, Vol. 21, No. 7, pp. 600-619.

Saks, A.M. and Gruman, J.A. (2011), "Getting newcomers engaged: The role of socialization tactics”, Journal of Managerial Psychology, Vol. 26, No. 5, pp. 383-402.

Salanova, M., Agut, S. and Peiró, J.M. (2005), "Linking organizational resources and work engagement to employee performance and customer loyalty: the mediation of service climate", Journal of Applied Psychology, Vol. 90, No. 6, pp. 1217-1227.

Salanova, M., Bakker, A.B. and Llorens, S. (2006), "Flow at work: Evidence for an upward spiral of personal and organizational resources", Journal of Happiness Studies, Vol. 7, No. 1, pp. 1-22.

Sapyaprapa, S., Tuicomepee, A. and Watakakosol, R. (2013), "Validation of psychological capital questionnaire in Thai employees", in: Proceedings of the Asian Conference on Psychology and the Behavioral Sciences, Japan, pp. 394-400.

Schaufeli, W.B. and Bakker, A.B. (2004), "Job demands, job resources, and their relationship with burnout and engagement: A multi-sample study", Journal of Organizational Behavior, Vol. 25, No. 3, pp. 293-315.

Schaufeli, W.B. and Taris, T.W. (2014), "A critical review of the Job DemandsResources Model: Implications for improving work and health”, in: Baur, G. 
F. and Hamming, 0. (eds.) Bridging occupational, organizational and public health, pp. 43-68, Springer, Netherlands.

Schaufeli, W.B., Salanova, M., González-Romá, V. and Bakker, A.B. (2002), “The measurement of engagement and burnout: A two sample confirmatory factor analytic approach", Journal of Happiness studies, Vol. 3, No. 1, pp. 71-92.

Seligman, M. E. P., and Csikszentmihalyi, M. (2000), "Positive Psychology-An Introduction”, American Psychologist, Vol. 55, No. 1, pp. 5-14.

Serrano, S.A. and Reichard, R.J. (2011), "Leadership strategies for an engaged workforce", Consulting Psychology Journal: Practice and Research, Vol. 63, No. 3, pp. 176-189.

Shuck, B. and Wollard, K. (2010), "Employee engagement and HRD: A seminal review of the foundations", Human Resource Development Review, Vol. 9, No. 1, pp. 89-110.

Soane, E., Shantz, A., Alfes, K., Truss, C., Rees, C. and Gatenby, M. (2013), "The association of meaningfulness, well-being, and engagement with absenteeism: a moderated mediation model", Human Resource Management, Vol. 52, No. 3, pp. 441-456.

Sobel, M.E. (1982), "Asymptotic confidence intervals for indirect effects in structural equation models", Sociological Methodology, Vol. 13, pp. 290-312.

Sortheix, F.M., Dietrich, J., Chow, A. and Salmela-Aro, K. (2013), "The role of career values for work engagement during the transition to working life", Journal of Vocational Behavior, Vol. 83, No. 3, pp. 466-475.

Steger, M.F., Dik, B.J. and Duffy, R.D. (2012), "Measuring meaningful work: The work and meaning inventory (WAMI)", Journal of Career Assessment, Vol. 20, No. 3, pp. 322-337.

Storm, K. and Rothmann, S. (2003), "A psychometric analysis of the Utrecht Work Engagement Scale in the South African police service", SA Journal of Industrial Psychology, Vol. 29, No. 4, pp. 62-70.

Thomas, T.P. (2013), “The effect of personal values, organizational values, and personorganization fit on ethical behaviors and organizational commitment outcomes among substance abuse counselors: A preliminary investigation", DRCE thesis, The University of Iowa, IOWA.

Van den Broeck, A., Vansteenkiste, M., De Witte, H. and Lens, W. (2008), "Explaining the relationships between job characteristics, burnout, and engagement: The role of basic psychological need satisfaction", Work \& Stress, Vol. 22, No. 3, pp. 277-294.

Van den Heuvel, M., Demerouti, E., Bakker, A.B. and Schaufeli, W.B. (2010), "Personal resources and work engagement in the face of change", Contemporary occupational health psychology: Global perspectives on research and practice, Vol. 1, pp. 124-150.

Van Veldhoven, M.J.P.M. and Meijman, T.F. (1994), The measurement of psychosocial job demands with a questionnaire (VBBA), Amsterdam: NIA.

Wilson, S.M. and Ferch, S.R. (2005), "Enhancing resilience in the workplace through the practice of caring relationships", Organization Development Journal, Vol. 23, No. 4, pp.45-60.

Xanthopoulou, D., Bakker, A.B., Demerouti, E. and Schaufeli, W.B. (2009), "Reciprocal relationships between job resources, personal resources, and work engagement", Journal of Vocational behavior, Vol. 74, No. 3, pp. 235-244. 
Xanthopoulou, D., Bakker, A.B. and Fischbach, A. (2013), "Work engagement among employees facing emotional demands", Journal of Personnel Psychology, Vol. 12, No. 2, pp. 7484.

Xanthopoulou, D., Bakker, A.B., Demerouti, E. and Schaufeli, W.B. (2007), "The role of personal resources in the job demands-resources model", International journal of stress management, Vol. 14, No. 2, pp.121-141. 